\title{
Attitude: A Determinant of Agricultural Graduates' Participation in Videoconferencing Technology
}

\author{
M. S. Meena (Corresponding author) \\ Division of Socio-Economics \& Extension \\ ICAR Research Complex for Eastern Region (P.O. BVC), Patna-800 014 (Bihar), India
}

Tel: 91-947-046-5688 E-mail: ms101@sify.com, ms101@rediffmail.com

\author{
K. M. Singh \\ Division of Socio-Economics \& Extension \\ ICAR Research Complex for Eastern Region (P.O. BVC), Patna-800 014 (Bihar), India
}

Tel: 91-943-106-0157Ｅ-mail: m.krishna.singh@gmail.com

\author{
H. R. Meena \\ Division of Extension Education \\ Indian Veterinary Research Institute, Izatnagar (UP), India \\ Tel: 91-941-237-1672Ｅ-mail: drhrmeena@ivri.res.in
}

Manish Kanwat

ICAR Research Centre for NEH Region, AP Centre, Basar, Arunachal Pradesh, India

Tel: 91-756-891-2689_E-mail: kanwat_manish1980@yahoo.co.in

Received: April 25, 2011

Accepted: May 9, 2011 Online Published: December 1, 2011

doi:10.5539/jas.v4n1p136

URL: http://dx.doi.org/10.5539/jas.v4n1p136

\begin{abstract}
The study envisaged to evaluate the attitude of agricultural graduates towards Videoconferencing (VC) technology. Study focused at persuasion stage of adoption process of innovations. A Likert-type-scale was developed, which consisted of 23-items. The scale instrument had four sections, viz., training, distance learning, agricultural communication and extension management. Cronbach's alpha coefficient $(\alpha=0.85)$ of reliability test was measured. Instrument was administered to randomly selected, seventy agricultural graduates of Punjab Agricultural University (PAU), Ludhiana, India during 2006-07 academic years. Attitude survey proved insightful with agricultural students. They had positive attitude in applied areas of VC technology, viz. training, distance learning, agricultural communication and extension management. Significant difference between users and non-users of VC technology was observed. Users had significant positive attitude towards VC technology. An enhanced understanding of attitudes is imperative before effective intervention strategies to moderate attitudes for enhancing acceptance and implementation of $\mathrm{VC}$ technology. Including transfer of agricultural innovations, VC can be encouraged in services like training, distance education, extension management, communication, administration, health, education and knowledge sharing. For these, infrastructure available within National Agricultural Research System (NARS), India can be effectively utilized for learning and technical counseling. This study adds value to the body of knowledge in evaluation and theory building from attitude perspective. As standard methodology is lacking to comprehend mindset of agricultural students, it will serve foundation for other future investigations.
\end{abstract}

Keywords: Attitude, Agricultural students, Videoconferencing, Technology 


\section{Introduction}

About 11900 agricultural graduates pass out every year in India, of which, hardly 2000 get employed in public and private sectors (Meena and Jain, 2003). Employment opportunities are declining due to reduction in cadre strength, both in government and private sector. Hence, creating better opportunities for agricultural graduates is a challenging task. Diversified agriculture can offer numerous career opportunities as well as lucrative options in farming, horticulture, dairying and animal husbandry and other domains of agriculture. Need based information with regard to improved agricultural practices, better employment opportunities etc., can only be made accessible through Information and Communication Technologies (ICTs). Benefits in utilization of ICTs for agricultural extension and training purposes are well documented (Hafkin and Odame, 2002; Richardson, 2005). ICTs can be used to increase effectiveness and efficiency of extension work and also helps farmers to utilize such information in solving their pressing problems (Klink in Leeuwis, 2004). As a communication tool, Videoconferencing (VC) can play a pivotal role. Student satisfaction with VC and web based learning can be expected to be high (Valents et al., 2001). Future of this technology, particularly in rural professional education is prominent (Du and Simpson, 2002; Lant, 2002; MacIntosh, 2002), however, it is still out of reach in many developing countries where it is most needed (Ekblad, 2004). VC is an enormously useful adjunct to traditional educational delivery modes, and can enable quality education opportunities that would otherwise be prohibitive due to time, travel, and cost constraints (Birden and Page, 2005).

In Indian context, success of VC technology has already been demonstrated. MANAGE (National Institute of Agricultural Extension Management, Hyderabad, India) an autonomous organization under Ministry of Agriculture and Cooperation, Government of India has successfully conducted communication and learning sessions in different villages for rural community (Reddy, 2003). Virtual Academy for Semi-Arid Tropics (VASAT) which is an informal virtual information communication and capacity building coalition has also used VC technology effectively to bring experts and farmers together, to enhance their reach and impact on knowledge empowerment of rural communities. It facilitated information communication between them starting from the stage of selection of suitable varieties till post-harvest management, animal health, management and distance learning aspects (Dixit et al., 2007). Many authors have successfully experimented with VC technology in diverse areas. The justification of using $\mathrm{VC}$ in education may come from concepts and principles of social learning (Abbey, 2000). It is often used for large groups, colleges and universities as distance learning and web based courses (Gehris, 1998). Attitude of agricultural students towards VC technology is one of the major components of human behavior for further action. Strong attitudes have more impact on behavior, are less susceptible to self-perception effects, and more stable over time (Holland et al., 2002). Hence, there was dire need to measure the attitude of agricultural students before putting effective intervention strategies for moderating their attitudes. The study formulated with the specific objectives: (i) to study demographic attributes (ii) to determine information source utilization, and (iii) to measure the attitude of agriculture graduates towards VC technology.

\section{Research Methods}

Before developing an attitude scale, related available instruments were initially examined. Due to lack of specific instrument, a Likert-type-scale developed which consisted of 23 -items. Cronbach's alpha coefficient $(\alpha=0.85)$ of reliability test was measured, which indicates a good internal consistency (George and Mallery, 2003). This instrument was administered to randomly selected, seventy agricultural graduates of Punjab Agricultural University (PAU), Ludhiana, India during 2006-07 academic years. Data were solicited through personal interview method and scale was used to assess level of agreement on items dealing with VC technology. Respondents rated their levels of agreement using following scale: 1=Strongly Disagree; 2=Disagree; 3=Undecided; 4=Agree; 5=Strongly Agree. Possible minimum and maximum score were 23 and 115, respectively. Finally, attitude scale was further categorized according to applied areas of VC technology namely; training $(\alpha=0.95)$, distance learning $(\alpha=0.90)$, agricultural communication $(\alpha=0.92)$ and extension management $(\alpha=0.89)$ aspects. Data were solicited on variables such as age (AGE), education (EDU), marital status (MSATUS), gender (GEN), land holding (LHOLDING), and training (TRG), information source utilization (ISU) and attitude (ATTITUDE). Data were statistically analyzed using SPSS 11.0. A summary of description of variables is presented in table 1.

\section{Results and Discussion}

\subsection{Demographic Attributes}

Among 70 agricultural students, $91.42 \%$ were over 29 years of age and $8.58 \%$ were between 19 and 29 years. Most of the students were male $(85.72 \%)$ and unmarried $(94.28 \%)$ and about fifty percent $(47.14 \%)$ had 
obtained their bachelors degree followed by masters $(40 \%)$ and doctoral degree $(12.86 \%)$ in agricultural sciences. Almost half of the students (44.29\%) were from landless families, around one-third (31.42\%) had land up to 10 acres, $14.28 \%$, between $11-20$ acre and only $10 \%$ had more than 20 acres of land. Majority (41.42\%) of agriculture students had attended long-term training, followed by short-term training $(11.42 \%)$ in their respective areas of specialization. Few of them, also attended trainings in dairying, tractor repairing and rice milling technology (Table 2).

\subsection{Information Source Utilization}

Data on information source utilization were obtained on three-point continuum namely always, sometimes and never (Table 3). Newspaper was the most sought after source of information ( $94.28 \%)$, followed by television $(81.42 \%)$, internet $(69.58 \%)$, group discussion $(67.14 \%)$, and visits to research institutes $(58.57 \%)$, radio $(51.42 \%)$, and research journals (48.58 \%). About fifty percent of them were already exposed to VC technology.

\subsection{Attitude towards VC Technology}

Attitude of agricultural students towards VC technology was assessed through applied areas of VC technology namely training, distance learning, agricultural communication and extension management. Mean values of statements varied from 3.14 to 4.22 , whereas, standard deviations (SD) ranged from 0.53 to 1.15 (table 4). Mean value of more than 4 showed a departure from agree to strongly agree about a particular attitude statement. Mean value of 3 to 4 showed a good signal towards moving to agreeing situation from an undecided situation. Low standard deviations implied a close agreement with participants' ratings whereas high standard deviations show variations in response.

\subsubsection{Training}

Training is an essential process to increase knowledge, change attitudes and to develop skills. It enhances self-confidence, competency and proficiency in communicating desired knowledge among peers and clients. The mean value of responses obtained under training aspect varied from 3.50 to 4.12. Agricultural students were of the view that $\mathrm{VC}$ technology reduces unproductive travel time, saves money and energy $(x=4.12 ; \sigma=0.67)$. VC is an interactive and comprehensive learning technique like other interpersonal transactions $(x=4.01 ; \sigma=0.71)$. A number of agricultural students, staff and farmers can be trained $(x=3.98 ; \sigma=0.87)$ through this facility. It reduces trainers-to-trainees ratio many folds $(x=3.72 ; \sigma=0.79)$. The respondents also felt that planning for VC can be done at a short notice $(x=3.50 ; \sigma=1.07)$. In developing countries, regular and systematic training for agricultural students, extension personnel and farmers usually gets hampered due to inadequate number of qualified trainers and increasing cost of training and this creates a lag in transfer of technology. In this context $\mathrm{VC}$ offers a better solution and researchers experienced that students and teachers are generally positive about VC technology but needs systematic training to exploit this technology (Pitcher et. al., 2000).

\subsubsection{Distance Learning}

Agricultural students agreed that VC technology provides quality learning to wider audience over distances $(x=4.05 ; \sigma=0.96)$ and also provides global educational, cultural information and knowledge in a network environment $(x=4.22 ; \sigma=0.67)$. VC offers information to institutions, learners and researchers with limited resources $(x=3.98 ; \sigma=0.95)$ and has technological feasibility of having meaningful dialogue between experts and students by virtually connecting remote ends. Instead of lectures at study centers, special lectures can be delivered and practical training can be imparted through VC. VC can be of immense advantage to students in attending classes from distant locations. Indian universities and educational institutions like Indira Gandhi National Open University (IGNOU), New Delhi have started imparting distance education in agriculture, putting $\mathrm{VC}$ to good use. However, issues of economic viability need to be addressed in due course of time.

\subsubsection{Agricultural Communication}

The role of VC technology as a communication medium is imperative. Agricultural students responded that VC is a language neutral medium and provides face-to-face communication with instructors ( $x=4.15 ; \sigma=0.73)$, as it delivers information in more convenient manner $(x=4.08 ; \sigma=0.73)$ and also reduces travel related costs $(x=4.04 ; \sigma=0.89)$. It disseminates information far quicker than other means $(x=3.82 ; \sigma=0.76)$ and improves the efficiency of experts and extension workers in reaching a large number of farmers with less effort $(x=3.91$; $\sigma=0.82$ ). It also reduces money and labor involved in organizing / demonstration / producing video films and publishing farm literature $(x=3.88 ; \sigma=1.07)$. Multiple site connectivity through $\mathrm{VC}$ helps participating institutions to have a face-to-face dialogue with renowned agricultural scientists and policy makers $(x=3.82$; $\sigma=0.88)$. VC technology can help the agriculture students' to intensify their motivation level and in learning communication skills. 


\subsubsection{Extension Management}

Extension management is an important issue. Study reveals that agriculture students were not much aware about extension management issues. However, they agreed that $\mathrm{VC}$ technology can improve quality of extension management $(x=4.02 ; \sigma=0.72)$ as $\mathrm{VC}$ links persons isolated by space $(x=3.88 ; \sigma=0.71)$ and by integration of $\mathrm{VC}$ into extension system, efficiency and effectiveness can be increased ( $\underline{x}=3.97 ; \sigma=0.53)$. This technology provides methods to explore techniques of managing people and services $(x=3.72 ; \sigma=0.72)$ and through this technology hands-on experience is favored $(x=3.31 ; \sigma=0.94)$. VC technology allows even shy people to interact $(x=3.14 ; \sigma=1.15)$ and people feel satisfied even though no contact or affinity exists between trainers and trainees $(x=3.20 ; \sigma=1.04)$. Interactive improvement in teaching skill is also possible though this facility $(x=3.22 ; \sigma=1.09)$. The study reveals that most of agricultural students $(78.58 \%)$ had favorable attitude towards $\mathrm{VC}$ technology (table 5). Fig-1 depicts average values of attitudes of students. They had favorable attitude ( $x=4.08)$ on training and distancing learning $(x=4.06)$ aspects of VC technology. Although, response on agricultural communication aspect had $(x=3.95)$ very close to agreeing situation. Their attitude was less favorable in extension management $(x=3.55)$ which may be due to lack of working experience with VC technology. Increasing concern over efficiency and effectiveness of technology transfer through this medium has made it emerge as an alternative method for managing people and services. It links students isolated by time and space and provides an interactive and face-to-face environment to conduct electronic meetings, tele-seminar, tele-training, teleconferences and distance education. Attitude survey proved insightful with agricultural students and there was a significant difference between users and non-users of $\mathrm{VC}$ technology $(t$ value $=18.23 ; d f=34$; $\mathrm{P}>1 \%)$. Users also had significant positive attitude as compared to non-users $(t$ value $=5.11 ; d f=34 ; \mathrm{P}>1 \%)$ of this promising technology. Positive attitude depicts a clear expression for adoption. Undoubtedly, there is a need to create awareness among agricultural graduates especially among non-users to bring attitudinal change in their outlook. VC may offer new possibilities for schools, colleges including formal instructions, connection with guest speakers and experts, multi-school project collaborations, professional activities etc. Consideration should therefore, be given to increasing the role of $\mathrm{VC}$ in expanding social as well as academic opportunities for rural masses and students. However, landscape of $\mathrm{VC}$ is changing and evolving quiet rapidly and educational institutions are now putting support systems in place to make technology easier to use. Implementation and greater adoption of $\mathrm{VC}$ technology can be facilitated through providing adequate access to equipment and technical support, addressing issues of time and scheduling, and providing sustained training.

\section{Conclusions and Recommendation}

Attitude is a complex mental process which is relatively stable and, once adopted, can provide a long-term positive effect. The study indicates positive attitude of agricultural students towards VC technology. Most of the students were well educated, which enabled them to access and make sense of information available. In Indian perspective, $\mathrm{VC}$ technology has a wider scope and can prove to be a boon for transfer of agricultural innovations. Following measures can be recommended for its wider application:(i) Besides transfer of agricultural technologies, more services such as training, distance education, extension management, communication, administration, health, education, and knowledge sharing may be encouraged (ii) VC infrastructure that already exists within National Agricultural Research System (NARS) which include, Indian Council of Agricultural Research (ICAR), State Agricultural Universities (SAUs) and Krishi Vigyan Kendra (KVKs) may be effectively put to use for learning and technical counseling (iii) Knowledge generation institutions must be encouraged to keep pace with changing scenario and develop content that can be put to use by using new tools (iv) Large scale interactive demonstrations must be organized (v) Technological change based on clients feedback (agriculture students, farmers etc.,) should be incorporated, and (vi) Understanding of VC technology must be built into system to gear-up for serving the farming community.

\section{References}

Abbey, B. (2000). Instructional and Cognitive Impacts of Web-Based Education. Pennsylvania: Idea Group Publishing.

Birden, H. \& Page, S. (2005). Teaching by Videoconference: A Commentary on Best Practice for Rural Education in Health Professional. Rural and Remote Health, 5 (356), 1-7 [Online] Available: http://rrh.deakin.edu.au (December 10, 2010).

Dixit, S. Balaji, V. \& Ramakrishna, S. (2007). Videoconferencing for Virtual Farmer-Expert Meet $10^{\text {th }}$ National Conference on E-Governance Held at Bhopal Organized by Department of Information and Technology, Government of Madhya Pradesh. pp. 126-130. 
Du, Y. \& Simpson, C. (2002). Effects of Learning Styles and Class Participation on Students' Enjoyment Level in Distributed Learning Environments. Proceedings, Annual Conference of Association for Library and Information Science Education, 15-18 January 2002, New Orleans, LA, USA.

Gehris, D. O. (1998). Using Multimedia Tools and Applications on Internet. California: Integrated Media Group.

George, D. \& Mallery, P. (2003). SPSS for Windows Step by Step: A Simple Guide and Reference.11.0 Update. Fourth Edition. Boston, MA: Allyn \& Bacon.

Hafkin, N. J. \& Odame, D. H. (2002). Gender, ICTs and Agriculture. A Situation Analysis of $5^{\text {th }}$ Consultative Expert Meeting of CTA, ICT Observatory Meeting on Gender and Agriculture in Information Society, 11-13 September, CTA, Wageningen.

Hildebrand, E. J. (1995). Videoconferencing in Business Curriculum. Journal of Business and Technical Communication, 9 (2), pp: 228-240. http://dx.doi.org/10.1177/1050651995009002005

Holland, R. W. Verplanken, B. \& Knippenberg, A. (2002). On Nature of Attitude-Behavior Relations: Strong Guide, Weak Follow. European Journal of Social Psychology, 32, 869-876. http://dx.doi.org/10.1002/ejsp.135

Lant, K. M. (2002). Flesh and Bone: Information Literacy, Teaching and Connected Classroom: In: Teaching, Learning, \& Technology: The Connected Classroom. Proceedings, Annual Mid-South Instructional Technology Conference. 7-9 April 2002, Murfreesboro, TN, USA. [Online] Available: http:/www.mtsu.edn/itconf/proceed02/index.html (January 12, 2010).

Leeuwis, C. (2004). Communication for Rural Innovation: Rethinking Agricultural Extension, $3^{\text {rd }}$ edn. Oxford: Blackwell.

MacIntosh, J. MacKay, E. Mallet-Boucher, M. \& Wiggins, N. (2002). Discovering Co-Learning with Students in Distance Education Sites. Nurse Educator, (27), pp.182-186. http://dx.doi.org/10.1097/00006223-200207000-00012

Meena, M. S. \& Jain, R. K. (2003). Agri-Clinics: Boon for Quality Services. Extension Bulletin Published from Central Institute of Post-Harvest Engineering \& Technology, Ludhiana (India).

Pitcher, N. Davidson, K. \& Napier, J. G. (2000). Videoconferencing in Higher Education. Innovations in Education and Teaching International, 37 (3), pp. 199-209.

Richardson, D. (2005). How Can Agricultural Extension Best Harness ICTs to Improve Rural Livelihoods in Developing Countries. In: Gelb, E and Offer, A. (Eds.), ICT in Agriculture: Perspectives of Technological Innovation. Jerusalem: Hebrew University of Jerusalem, Center for Agricultural Economic Research.

Smith, E. R. \& Mackie, D. M. (2000). Social Psychology, 2nd ed., Psychology Press, Philadelphia, PA.

Valents, A. Therrault, D. Dieter, M. \& Mrtek, R. (2001). Identifying Student Attitudes and Learning Styles in Distance Education. Journal Asynchronous Learning Networks, [Online] Available: http:/www.aln.org/alnweb/journal/vol5_issue2/valents/valenta.htm (December 25, 2009).

Table 1. Description Summary of Variables in Attitude Study

\begin{tabular}{|l|l|}
\hline Variables & Definition \\
\hline AGE & Age of respondents in years \\
\hline EDU & Number of years spent by respondents in a formal institution \\
\hline MSTATUS & Value is 1 if respondents is married and 0 otherwise \\
\hline GEN & Value is 1 if respondents is male and 2 for female \\
\hline LHOLDING & Land in hectares \\
\hline TRG & Value is assigned as: $1=$ short-term training, $2=$ medium-term training, and, $3=$ long-term training \\
\hline ISU & $\begin{array}{l}\text { Value is assigned according to frequency of information source used: } 0=\text { never, } 1=\text { sometimes, } \\
\text { and } 2=\text { always }\end{array}$ \\
\hline ATTITUDE & Rating scale: $1=$ Strongly Disagree; $2=$ Disagree; $3=$ Undecided; $4=$ Agree; $5=$ Strongly Agree \\
\hline
\end{tabular}


Table 2. Demographic Attributes of Agriculture Students, PAU, Ludhiana (Punjab)

\begin{tabular}{|c|c|c|c|}
\hline Demographic Attributes & & Frequency & $(\%)$ \\
\hline \multicolumn{4}{|l|}{ Age (in years) } \\
\hline Low & $(<19)$ & - & - \\
\hline Medium & $(19-29)$ & 6 & 8.58 \\
\hline High & $(>29)$ & 64 & 91.42 \\
\hline \multirow[t]{3}{*}{ Education } & Bachelor of Technology & 33 & 47.14 \\
\hline & Master of Science & 28 & 40.00 \\
\hline & Doctor of Philosophy & 9 & 12.86 \\
\hline \multirow[t]{2}{*}{ Marital Status } & Married & 4 & 5.72 \\
\hline & Unmarried & 66 & 94.28 \\
\hline \multirow[t]{2}{*}{ Gender } & Male & 60 & 85.72 \\
\hline & Female & 10 & 14.28 \\
\hline \multirow[t]{4}{*}{ Land Holding (in hectares) } & Landless & 31 & 44.29 \\
\hline & $1-10$ & 22 & 31.42 \\
\hline & $11-20$ & 10 & 14.28 \\
\hline & $>20$ & 7 & 10.00 \\
\hline \multicolumn{4}{|l|}{ Training Attended } \\
\hline \multirow[t]{3}{*}{ Agriculture } & Short-term & 8 & 11.42 \\
\hline & Medium & 6 & 8.57 \\
\hline & Long-term & 29 & 41.42 \\
\hline \multirow[t]{3}{*}{ Dairying } & Short-term & - & - \\
\hline & Medium & 9 & 12.85 \\
\hline & Long-term & 3 & 4.28 \\
\hline \multirow[t]{3}{*}{ Tractor Repairing } & Short-term & 1 & 1.42 \\
\hline & Medium & 1 & 1.42 \\
\hline & Long-term & 2 & 2.86 \\
\hline Rice Milling Technology & Long-term & 2 & 2.86 \\
\hline
\end{tabular}

Table 3. Information Source Utilization of Agriculture Graduates, PAU, Ludhiana, (Punjab)

\begin{tabular}{|l|l|l|l|}
\hline Information sources utilization & \multicolumn{4}{|l|}{ Frequency (\%) } \\
\hline & Never (\%) & Sometimes (\%) & Always (\%) \\
\hline Radio & $3(4.28)$ & $36(51.42)$ & $31(44.28)$ \\
\hline Television & - & $13(18.58)$ & $57(81.42)$ \\
\hline News Paper & - & $4(5.72)$ & $66(94.28)$ \\
\hline Group Discussion & $10(14.28)$ & $47(67.14)$ & $13(18.58)$ \\
\hline Research Institute Visit & $14(20.00)$ & $41(58.57)$ & $15(21.42)$ \\
\hline Research Journal & $12(17.14)$ & $36(48.58)$ & $24(34.28)$ \\
\hline Internet & $4(5.71)$ & $17(24.14)$ & $49(69.58)$ \\
\hline Videoconferencing & $36(51.43)$ & $29(41.43)$ & $5(7.14)$ \\
\hline
\end{tabular}

Figures in the parentheses indicate percentage of each source of information. 
Table 4. Agricultural Graduates' Attitude towards VC technology, PAU, Ludhiana (Punjab)

\begin{tabular}{|c|c|c|}
\hline Statements Rated & $\begin{array}{l}\text { Mean } \\
(\bar{x})\end{array}$ & $\begin{array}{l}\text { Standard } \\
\text { Deviation }(\sigma)\end{array}$ \\
\hline \multicolumn{3}{|l|}{ Training } \\
\hline VC reduces unproductive travel time, money and energy & 4.12 & 0.67 \\
\hline $\begin{array}{l}\text { VC offers an interactive and comprehensive learning like other interpersonal } \\
\text { transaction }\end{array}$ & 4.01 & 0.71 \\
\hline By using VC technology more number of staffs and farmers can be trained & 3.98 & 0.87 \\
\hline VC reduces trainers-to-trainees' ratio many folds & 3.72 & 0.79 \\
\hline VC can be planned in short notice & 3.50 & 1.07 \\
\hline \multicolumn{3}{|l|}{ Distance Learning } \\
\hline VC provides quality learning to wider audience over distance & 4.05 & 0.96 \\
\hline $\begin{array}{l}\text { VC offers information to learners, researchers and institutions with limited } \\
\text { resources }\end{array}$ & 3.98 & 0.95 \\
\hline $\begin{array}{l}\text { VC can provide global educational, cultural information, and knowledge in a } \\
\text { network environment }\end{array}$ & 4.22 & 0.67 \\
\hline \multicolumn{3}{|l|}{ Agricultural Communication } \\
\hline $\begin{array}{l}\mathrm{VC} \text { is a language neutral medium which provides face-to-face communication } \\
\text { with instructors }\end{array}$ & 4.15 & 0.73 \\
\hline VC disseminates information quicker than other means of communication & 3.82 & 0.76 \\
\hline $\begin{array}{l}\text { VC improves efficiency of experts and extension workers in reaching a large } \\
\text { number of farmers with less effort }\end{array}$ & 3.91 & 0.82 \\
\hline VC delivers information in more convenient manner & 4.08 & 0.73 \\
\hline VC reduces travel related cost & 4.04 & 0.89 \\
\hline $\begin{array}{l}\text { VC reduced money and labor involved in organizing / demonstration / producing } \\
\text { video films and publishing farm literature }\end{array}$ & 3.88 & 1.07 \\
\hline $\begin{array}{l}\text { Multiple site connectivity through VC helped in face-to-face dialogue with } \\
\text { renowned agricultural scientists and policy makers }\end{array}$ & 3.82 & 0.88 \\
\hline \multicolumn{3}{|l|}{ Extension Management } \\
\hline VC improves quality of extension management & 4.02 & 0.72 \\
\hline VC links persons isolated by space & 3.88 & 0.71 \\
\hline $\begin{array}{l}\text { By integration of VC into extension system, efficiency and effectiveness could be } \\
\text { increased }\end{array}$ & 3.97 & 0.53 \\
\hline VC provides methods to explore techniques of managing people and services & 3.72 & 0.72 \\
\hline Through VC technology hands-on experience is favored & 3.31 & 0.94 \\
\hline Shy people can ask questions through VC facility & 3.14 & 1.15 \\
\hline People feel satisfaction as no contact or affinity between trainers and trainee & 3.20 & 1.04 \\
\hline Interactive improvement in teaching skill is possible though this facility & 3.22 & 1.09 \\
\hline
\end{tabular}

Table 5. Agricultural Graduates' Distribution based on their Attitude towards VC Technology, PAU, Ludhiana (Punjab)

\begin{tabular}{|l|l|l|l|}
\hline Attitude & & Frequency & (\%) \\
\hline Less Favorable & $<80$ & 7 & 10.00 \\
\hline Favorable & $80-95$ & 55 & 78.58 \\
\hline Most Favorable & $>95$ & 8 & 11.42 \\
\hline
\end{tabular}

